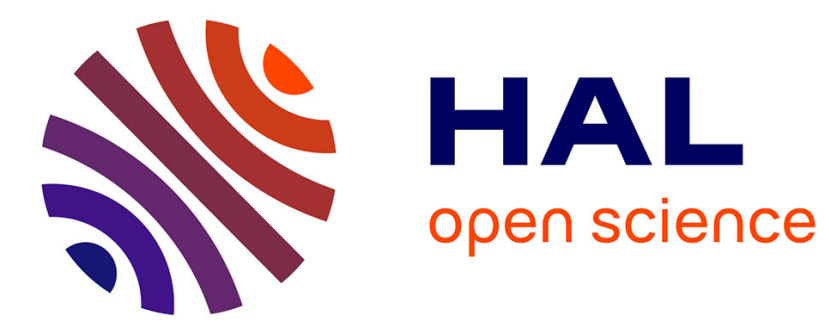

\title{
Kinetics and Product Formation during the Photooxidation of Butanol on Atmospheric Mineral Dust
}

\author{
M. Ponczek, C. George
}

\section{To cite this version:}

M. Ponczek, C. George. Kinetics and Product Formation during the Photooxidation of Butanol on Atmospheric Mineral Dust. Environmental Science and Technology, 2018, 52 (9), pp.5191-5198. 10.1021/acs.est.7b06306 . hal-01795833

\section{HAL Id: hal-01795833 \\ https://hal.science/hal-01795833}

Submitted on 18 Nov 2020

HAL is a multi-disciplinary open access archive for the deposit and dissemination of scientific research documents, whether they are published or not. The documents may come from teaching and research institutions in France or abroad, or from public or private research centers.
L'archive ouverte pluridisciplinaire HAL, est destinée au dépôt et à la diffusion de documents scientifiques de niveau recherche, publiés ou non, émanant des établissements d'enseignement et de recherche français ou étrangers, des laboratoires publics ou privés. 
Milena Ponczek and Christian George*

Univ Lyon, Université Claude Bernard Lyon 1, CNRS, IRCELYON, F-69626, Villeurbanne, France

*correspondence to: christian.george@ircelyon.univ-lyon1.fr

\section{Abstract}

11 Mineral dust particles have photochemical properties that can promote heterogeneous reactions on their surfaces and therefore alter atmospheric composition. Even though dust photocatalytic nature has received significant attention recently, most studies have focused on inorganic trace gases. Here we investigated how light changes the chemical interactions between butanol and Arizona test dust, a proxy for mineral dust, under atmospheric conditions. Butanol uptake kinetics were measured, exploring the effects of UV light irradiation intensity $(0-1.4 \mathrm{~mW} / \mathrm{cm})$, relative humidity $(0-10 \%)$, temperature (283 - $298 \mathrm{~K})$, and butanol initial concentration (20 - $55 \mathrm{ppb})$. The composition of the gas phase was monitored by a high-resolution proton-transfer-reaction mass spectrometer (PTR-ToFMS) operating in $\mathrm{H}_{3} \mathrm{O}^{+}$mode. Water was observed to play a significant role, initially reducing heterogeneous processing of butanol, but enhancing reaction rates once it evaporated. Gas phase

21 products were identified, showing that surface reactions of adsorbed butanol led to the emission of a variety of carbonyl containing compounds. Under actinic light these compounds will photolyze and

23 produce hydroxyl radicals, changing dust processing from a sink of VOC into a source of reactive compounds. 


\section{1 - Introduction}

Every year, large amounts of mineral dust are emitted into the atmosphere and transported over several kilometers before being deposited. For instance, Kaufman and coworkers estimated that 240 \pm 80 Tg of dust are transported annually from Africa to the Atlantic Ocean, and of these, 50 Tg arrives in the Amazon Basin. ${ }^{1}$ During their lifetime in the troposphere, dust particles undergo physical interactions, including absorbing and scattering light, which influences radiative forcing and global albedo, $^{2}$ and inducing chemical reactions when acting as a substrate for the conversion or scavenging of various trace gases. ${ }^{3}$ Heterogeneous reactions of atmospheric relevant trace gases on mineral aerosols have received more attention lately, and the uptake of a few reactive gases by mineral aerosols has been studied using a variety of experimental approaches. For instance, the uptake kinetics of inorganic compounds such as $\mathrm{NO}_{2}, \mathrm{HNO}_{3}, \mathrm{~N}_{2} \mathrm{O}_{5}, \mathrm{O}_{3}, \mathrm{SO}_{2},{ }^{4-7}$ as well as some organics ${ }^{8,9}$ were investigated on mineral dust and various proxies. However, few studies have explored the effect of irradiation on the uptake.

Suspended dust particle composition varies depending on its sources location and may contain variable amounts of semiconductor metal oxides that show photocatalytic activity, such as $\mathrm{TiO}_{2}$ and $\mathrm{Fe}_{2} \mathrm{O}_{3}$, whose application in wastewater and air treatment have been extensively studied. ${ }^{10-13}$ Recently, the photocatalytic nature of dust particles has been suggested and discussed. ${ }^{14,15}$ However, up to now, mineral dust, we investigated the uptake kinetics of butanol on Arizona test dust (ATD). We performed experiments under dark and illuminated conditions and measured uptake coefficients as a function of several experimental parameters, including initial VOC concentration, relative humidity, 51 external temperature, and light intensity. Additionally, we analyzed the gas phase products, 
evaluating the role of dust and the influence of light, whose effects are quantified and discussed.

Butanol was selected as a proxy for small alcohols (and/or oxygenated VOCs; OVOC) that are abundant in the atmosphere. OVOCs are generally emitted directly by anthropogenic sources, biogenic sources, or produced from the degradation of other VOCs (hydrocarbon oxidation). Butanol, specifically, is an alcohol that does not absorb light in the UV or visible regions, but its incomplete oxidation products can generate photochemically active radicals.

\section{2 - Experimental}

\section{Coated wall flow tube}

Experiments were performed in a horizontal coated wall flow tube reactor described in detail previously. ${ }^{23}$ The temperature was maintained constant during each experiment by circulating thermostatically controlled water around an outer jacket. Dust was coated on the inner surface of a removable Pyrex insert (id $0.55 \mathrm{~cm}$, length $20 \mathrm{~cm}$ ), which fit within a larger tube, providing good contact with the jacket. Seven actinic lamps (Phillips $20 \mathrm{~W}$ ) surrounded the reactor and could be switched on or off to modify the light intensity between 0 and $1.4 \mathrm{~mW} / \mathrm{cm}^{2}$ (see Supplementary Information, Figure S1) measured at the outer surface of the reactor. It is important to highlight that in this layout, UV light was irradiated from the back of the coatings, which were relatively thin $(\mu \mathrm{m})$ with a maximum absorption of $15 \%$ i.e., the film is mostly homogeneously illuminated. Also, our approach does not consider light scattering in the dust film. However, Dupart et $\mathrm{al}^{24}$ showed that this approach led, nevertheless, to similar uptake kinetics measured in more complex aerosol flow tube experiments where such limitations do not exist. Therefore, we believe that the light intensity measured is appropriate for the experiments described herein.

All experiments were carried out at atmospheric pressure using filtered dry air as a carrier gas at a total flow of $200 \mathrm{~mL} \mathrm{~min}{ }^{-1}$, except when stated otherwise. For humid experiments, water vapor 
was introduced into the reactor by bubbling air through a thermostated gas bubbler filled with deionized water. Humidity and temperature were monitored by a SP UFT75 sensor.A schematic overview of the experimental setup is given in Figure S3. Gas phase butanol was generated using a calibrated permeation tube (Dynacal ${ }^{\circledR}$ - permeation rate $100 \mathrm{ng} / \mathrm{min}$ at $60{ }^{\circ} \mathrm{C}$ ) placed in a temperaturecontrolled permeation device (VICI Metronics Dynacalibrator, Model 150).

Gas phase analysis

The coated wall flow tube was coupled to a high-resolution proton transfer reaction time of flight mass spectrometer (SRI-PTR-TOF-MS 8000 from Ionicon Analytik GmbH - Innsbruck, Austria) enabling on-line monitoring of the disappearance of butanol and the identification and quantification of products. The instrument continuously sampled $50 \mathrm{sccm}$ at the flow tube outlet and its inlet temperature was $60{ }^{\circ} \mathrm{C}$. Spectra were collected at a time resolution of $3.2 \mathrm{~s}$. All measurements were performed using the following parameters: source current of $4.6 \mathrm{~mA}$, drift voltage of $600 \mathrm{~V}$, drift temperature of $60^{\circ} \mathrm{C}$, and a drift pressure of $2.42 \mathrm{mbar}$. E/N was about $125 \mathrm{Td}\left(1 \mathrm{Td}=10^{-17} \mathrm{~V} \mathrm{~cm}{ }^{2}\right)$. All results presented here were acquired using the $\mathrm{H}_{3} \mathrm{O}^{+}$ionization mode as the reaction rates and fragmentation patterns for OVOCs such as alcohols, aldehydes, ketones, etc., have been extensively studied and documented. ${ }^{25-28}$

Ideally, the proton transfer reaction should provide soft ionization resulting in very little or no fragmentation of compounds. However, in practice, fragmentation is observed. Fragmentation patterns for small OVOCs have already been studied, but it may be altered depending on the actual experimental conditions (for example, humidity) and instrument settings. ${ }^{29}$ Therefore, fragmentation patterns of the main products were examined by measuring the signals of vaporized liquid standards under the same experimental conditions. Details about this procedure are available in the Supplementary Information.

\section{$\underline{\text { Film Preparation }}$}


105 Arizona Test Dust (ATD) was used as provided by Powder Technology Inc. without further 106 pretreatment. The ATD Brunauer - Emmett - Teller surface area (BET) is $4.2 \pm 0.012 \mathrm{~m}^{2} \mathrm{~g}^{-1}$ as 107 measured with a Micromeritics Tristar 3000, with particles having an average grain size of $4.08 \pm$ $108 \quad 2.91 \mu \mathrm{m}$.

ATD suspensions in ethanol were prepared to facilitate coating the inner surface of the Pyrex tube insert. These suspensions were sonicated for 10 minutes and then dripped into the insert, which was rotated to produce a uniform film. Once coated, the excess solution was allowed to flow out and the tube was dried by flowing nitrogen through it. This step was repeated few times until a visually homogeneous film was obtained. Finally, the insert was placed in an oven to dry at $60{ }^{\circ} \mathrm{C}$ for $24 \mathrm{~h}$.

114 After drying, all tubes were weighed, and the mass of ATD films varied from 20 to $150 \mathrm{mg}$.

\section{Uptake Experiments}

Butanol loss was measured as a function of the movable injector position, that is, interaction time between the VOC and dust surface. In a typical experiment, a freshly coated tube was placed in the reactor and the injector was set to bypass the reactor, so that no surface was exposed to the gas flow (position 0). The flow of butanol was then established and its concentration monitored. When it was constant, lights were switched on. After 60 minutes, the uptake measurements started by moving the injector stepwise (steps of $2 \mathrm{~cm}$ ), exposing the ATD surface for 10 minutes. The injector was then reset to position 0 for another 10 minutes. The procedure was repeated until the entire length of the coated tube was exposed, which is equivalent to 10 positions of $2 \mathrm{~cm}$ each.

$$
\ln \frac{C(0)}{C(t)}=k_{o b s} t
$$


$129 \mathrm{C}(0)$ and $\mathrm{C}(\mathrm{t})$ are the inlet and outlet concentrations of butanol after a reaction time $(\mathrm{t})$, and $\mathrm{k}_{\mathrm{obs}}$ is

130 the measured first order rate constant. The uptake coefficient can then be calculated according to:

131

$$
\gamma=\frac{4 k_{o b s}}{\langle v\rangle} \frac{V}{S_{\text {surf }}}
$$

132

133

134

135

136

$$
\gamma_{g e o}=\frac{2 r}{\langle v\rangle} k_{o b s}
$$

138 where $\mathrm{r}$ is the radius $\left(\mathrm{r}_{\text {tube }}=0.55 \mathrm{~cm}\right)$.

It is worth noting that the uptake coefficients reported here are at steady state, reached after 10 minutes of exposure, and not the initial uptake coefficients usually reported in the literature. ${ }^{4}$

\section{$\underline{\text { Diffusion correction }}$}

144 Uptake was corrected for diffusion effects that may form axial and radial concentration profiles along

145 the reactor, limiting the reaction rate. The method used, proposed by Cooney-Kim-Davis and derived 146 by Murphy and co-workers, ${ }^{30}$ assumes that in the boundary condition the analyte is adsorbed or reacts 147 with some characteristic probability on each wall collision, which is the corrected uptake coefficient. 148 We solved the differential equation numerically, as proposed by Li et al., ${ }^{31}$ where the corrected uptake 149 coefficient is given as function of the transmittance $(\mathrm{C} / \mathrm{Co})$. 


\section{$\underline{\text { Butanol Uptake Kinetics }}$}

For a solid film, the reactive surface area may be larger than the geometric surface area due to the presence of multiple layers of particles and/or because of the existence of pores. In the case of a fully accessible internal surface, the specific surface area can be used for the uptake calculations. Therefore, butanol uptake coefficients were measured as a function of dust film mass (Figure S3a). For these measurements, different fresh films of ATD were tested while other conditions were kept constant. The uptake coefficient increased linearly with the mass of the film, indicating that the entire inner surface is participating in the uptake process. ${ }^{4}$ Therefore, mass-dependent $\gamma_{\text {geo }}$ uptake coefficients were corrected by the BET surface area of the samples according to:

$$
\gamma_{B E T}=\gamma_{G e o} \frac{S_{\text {surf }}}{S_{B E T} m_{f i l m}}
$$

where $\mathrm{S}_{\mathrm{BET}}$ is the BET surface area and $\mathrm{m}_{\text {film }}$ is the mass coated in the sample holder tube. The BET-corrected uptake coefficients, reported below, were observed to be independent of the actual mass of the film (Figure S3b).

Uptake rates were measured for different initial (inlet) concentrations of butanol and were observed to decrease from $5.3 \times 10^{-7}$ to $2.2 \times 10^{-7}$ when the concentration increases from 20 to $55 \mathrm{ppb}$ (Figure S4). For an initial concentration of $800 \mathrm{ppb}$ ( $\pm 160 \mathrm{ppb})$ of butanol, uptake could not be detected, due to very rapid surface saturation. Initial uptake coefficients tend to be independent of concentration when all active sites on the fresh surface are available for adsorption/reaction. ${ }^{7,32} \mathrm{El}$

171 Zein et al. ${ }^{20}$ reported no concentration dependence for the initial uptake coefficient, whereas an 172 inverse dependence on initial $\mathrm{H}_{2} \mathrm{O}_{2}$ concentration was observed for steady state uptake. Nicolas et 173 al., ${ }^{16}$ using a similar experimental apparatus, also reported that both dark and irradiated uptake kinetics on titanium dioxide decreased inversely to initial ozone mixing ratio. 
When the temperature increased from 283 to $298 \mathrm{~K}$, the uptake coefficient decreased from 1.2 $\mathrm{x} 10^{-6}$ to $1.8 \times 10^{-7}$, which is approximately one order of magnitude (Figure S5). The reactive uptake coefficient reported herein represents the overall kinetics of the heterogeneous process, and therefore encompasses both chemical reactions and physical adsorption. Adsorption is an exothermic phenomenon favored by a decrease in temperature. ${ }^{33}$ Thereby, the temperature dependence suggests the importance of adsorption/desorption in the butanol uptake mechanism, even under reactive conditions. A similar dependence was previously reported for other VOCs. ${ }^{32,34}$

Humidity also has a strong influence on the uptake kinetics of butanol onto ATD (Figure S6). At $10 \%$ relative humidity, the uptake coefficient is $6 \%$ of the value measured under dry conditions, suggesting that water and butanol compete for available sites on the surface of ATD. To better understand the influence of relative humidity on butanol uptake, an ATD film was successively exposed to different relative humidity levels under dark conditions. First, the tube was exposed to air and butanol (20 ppb) under dry conditions, and the disappearance of butanol was recorded. Then, butanol flow was turned off and the tube was left under air until butanol was not detected. Thereafter, butanol flow was resumed and the sample was exposed to the VOC with 2\%, 5\%, and 10\% moisture. Between each relative humidity level, the sample was left under dry air flow for evacuation. The presence of water vapor in the feed stream significantly reduced butanol surface adsorption capacities (Figure S7). Surface saturation was faster at higher water vapor contents, up to $10 \%$ relative humidity, no change in butanol concentration was observed.

The uptake of water onto mineral particles has been studied by several authors and recently reviewed. ${ }^{35}$ However few studies have focused on the competitive uptake of water and other trace gases, particularly under irradiation. For pure $\mathrm{TiO}_{2}$, relative humidity has a positive effect up to about $30 \%$ relative humidity, as observed by Sassine et al., ${ }^{36}$ who reported that the uptake of formaldehyde increased from $6 \%$ to $30 \%$ relative humidity, and decreased at higher humidities. The influence of humidity seems to vary depending on the combination of trace gas and mineral studied, and results are often controversial. Under dark conditions using ATD and other realistic dust, regardless of the 


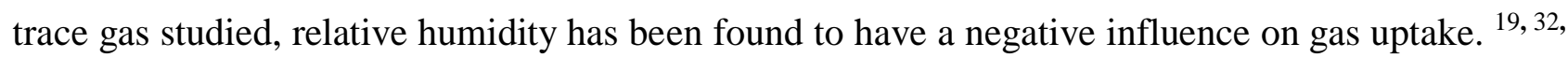
${ }^{37,38}$ Our results show that the presence of light did not change this negative trend for butanol uptake. In terms of competition between butanol and water for available surface sites, water molecules

204 are smaller and faster, giving them an advantage over butanol molecules. Regarding the affinity 205 between the mineral surface and water molecules, Gustafson and coworkers ${ }^{39}$ noted a difference 206 between $\mathrm{ATD}$ and $\mathrm{CaCO}_{3}$ isotherms in the sub-monolayer range, demonstrating stronger water-ATD 207 interactions compared to $\mathrm{CaCO}_{3}$. They proposed that the difference might be due to the higher 208 electronegativity of Si which increases the polarity of the - $\mathrm{OH}$ group, resulting in a stronger $\mathrm{H}$-bond 209 in the ATD. Furthermore, water adsorption capacity is related to other characteristics such as the 210 mineral composition, cation hydration energies, presence of swellable clay minerals, porosity, etc. ${ }^{40}$ 211 Interestingly, the system shows a hysteresis. When the ATD film was exposed to decreasing 212 levels of relative humidity under irradiation, butanol uptake increased more rapidly than was observed 213 for a freshly humidified surface (Figure 1). That is, water condensation may first reduce 214 heterogeneous processing, but its evaporation may afterwards change the surface characteristics to 215 enhance its reactivity. Water uptake measurements on ATD have shown that one monolayer of water 216 is developed at about $11 \%$ relative humidity. ${ }^{39}$ In going from dry to slightly humid conditions, 217 adsorbed water molecules dissociate leaving $\mathrm{OH}$ groups on the surface. By increasing relative 218 humidity, once surface is fully hydroxylated, extra water molecules will be accommodated in outer 219 layers via hydrogen bonds. ${ }^{41}$ Those surface $\mathrm{OH}$ groups can form $\mathrm{OH}$ radicals under dry conditions 220 and illumination, providing an additional pathway for butanol oxidation. 


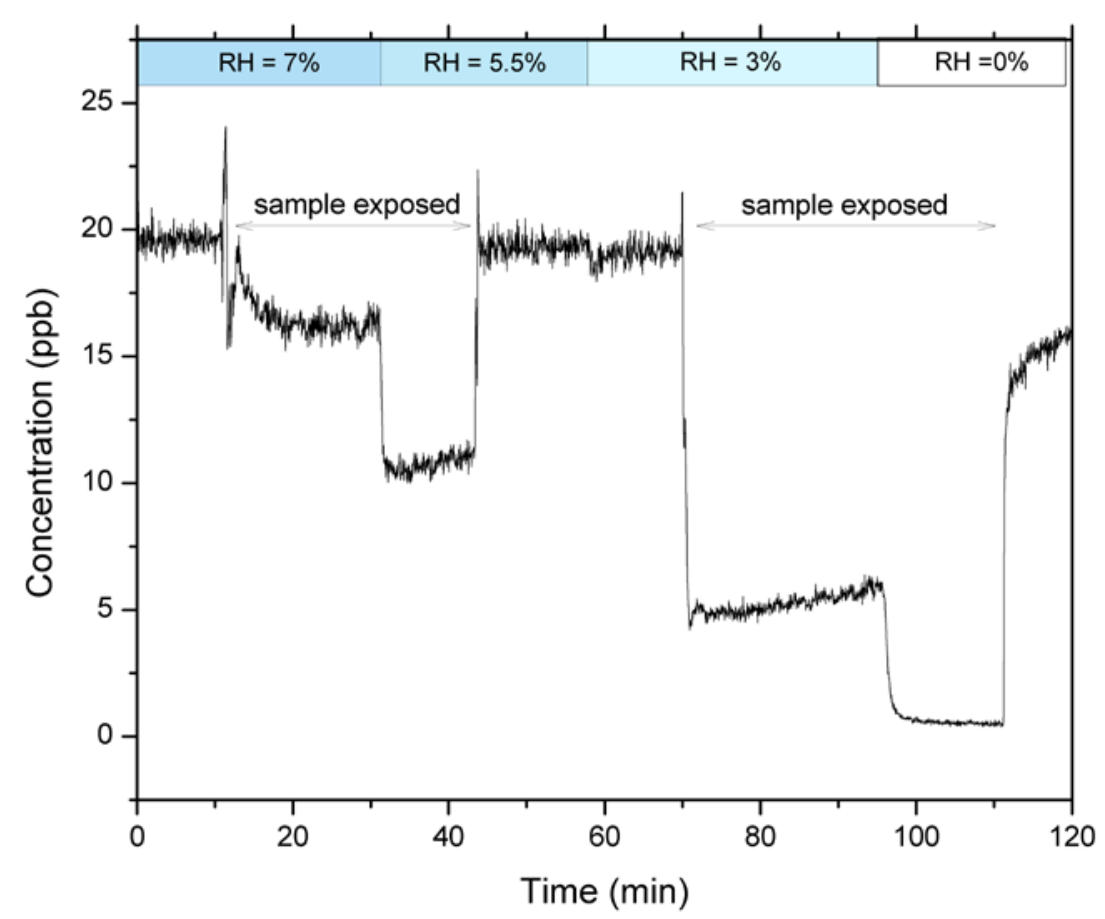

Figure 1: Decreasing relative humidity $(\mathrm{RH})$ and successively exposing the sample surface to butanol and $\mathrm{H}_{2} \mathrm{O}$ vapor. For butanol initial concentration of $20 \mathrm{ppb}$, temperature $=20^{\circ} \mathrm{C}$, 7 lamps, mass of ATD $=69 \mathrm{mg}$.

Our experimental setup allowed switching between 0 and 7 lamps in different geometrically symmetrical configurations. Each lamp emits UV-A radiation in the wavelength range from 300 to $420 \mathrm{~nm}$, with a maximum around $350 \mathrm{~nm}$. Figure S8 shows the systematic increase of the uptake coefficient as a function of UV light irradiance. The dark uptake coefficient is 5 times less than the light uptake coefficient for irradiation with 7 lamps. This gives clear evidence of the photochemical nature of the interactions between butanol (which does not absorb within this wavelength region) and ATD (which semiconductor content is activated by light). This is in agreement with previous studies which also observed photo-enhanced uptake for inorganic compounds over different mineral dust proxies. ${ }^{16-20,37,38}$ However, few similar studies on organic compounds are available. ${ }^{21}$ 
238 The uptake (loss) of butanol was accompanied by the formation of a variety of gas phase products 239 (Figure 2). Major products were observed at m/z $45.033\left(\mathrm{C}_{2} \mathrm{H}_{5} \mathrm{O}^{+}\right), 31.017\left(\mathrm{CH}_{3} \mathrm{O}^{+}\right), 59.049\left(\mathrm{C}_{3} \mathrm{H}_{7} \mathrm{O}^{+}\right)$, $24033.033\left(\mathrm{CH}_{5} \mathrm{O}^{+}\right), 69.069\left(\mathrm{C}_{5} \mathrm{H}_{9}{ }^{+}\right), 115.111\left(\mathrm{C}_{7} \mathrm{H}_{15} \mathrm{O}^{+}\right)$, and five other minor products were detected at 241 very low concentrations (below $0.1 \mathrm{ppb})$ at $83.085\left(\mathrm{C}_{6} \mathrm{H}_{11}{ }^{+}\right), 87.080\left(\mathrm{C}_{5} \mathrm{H}_{11} \mathrm{O}^{+}\right), 97.101\left(\mathrm{C}_{7} \mathrm{H}_{13}{ }^{+}\right)$, $242111.116\left(\mathrm{C}_{8} \mathrm{H}_{15}{ }^{+}\right)$, and $129.127\left(\mathrm{C}_{8} \mathrm{H}_{17} \mathrm{O}^{+}\right)$. Products identification is detailed in Table 1. It is 243 interesting to note that fragments with $\mathrm{m} / \mathrm{z}$ greater than butanol were also detected (for instance $\mathrm{m} / \mathrm{z}$ 24469.069 and $\mathrm{m} / \mathrm{z}$ 115.111), indicating the possibility of dimerization or recombination of intermediates. 245 It should be noted that m/z 31.017 is here assigned to formaldehyde, although other compounds may 246 interfere at this $\mathrm{m} / \mathrm{z}$, as discussed by Schirpp et al. and Inomata et al. ${ }^{42,43}$. No product formation was 247 observed in the dark.

Table 1: Product identification and $\mathrm{m} / \mathrm{z}$ to molecules assignments.

Major Products

m/z Formula Compound

$\begin{array}{lll}\text { 45.033 } & \mathrm{C}_{2} \mathrm{H}_{5} \mathrm{O}^{+} & \text {Acetaldehyde } \\ \mathbf{3 1 . 0 1 7} & \mathrm{CH}_{3} \mathrm{O}^{+} & \begin{array}{l}\text { Formaldehyde / } \\ \text { fragment Propanal }\end{array} \\ \mathbf{5 9 . 0 4 9} & \mathrm{C}_{3} \mathrm{H}_{7} \mathrm{O}^{+} & \begin{array}{l}\text { Propanal/ Acetone } \\ \text { 33.033 }\end{array} \\ \mathrm{CH}_{4} \mathrm{O}^{+} & \text {Metanol } \\ \mathbf{6 9 . 0 6 9} & \mathrm{C}_{5} \mathrm{H}_{9}^{+} & \begin{array}{l}\text { fragment Octanal / } \\ \text { Pentanal }\end{array} \\ \mathbf{1 1 5 . 1 1 1} & \mathrm{C}_{7} \mathrm{H}_{15} \mathrm{O}^{+} & \text {Heptanal }\end{array}$

\section{Minor Products}

\begin{tabular}{|ccl}
$\mathbf{m} / \mathbf{z}$ & Formula & Compound \\
$\mathbf{8 3 . 0 8 5}$ & $\mathrm{C}_{6} \mathrm{H}_{11}{ }^{+}$ & fragment Hexanal \\
$\mathbf{8 7 . 0 8 0}$ & $\mathrm{C}_{5} \mathrm{H}_{11} \mathrm{O}^{+}$ & Pentanal \\
$\mathbf{9 7 . 1 0 1}$ & $\mathrm{C}_{7} \mathrm{H}_{13}{ }^{+}$ & fragment Heptanal \\
$\mathbf{1 1 1 . 1 1 6}$ & $\mathrm{C}_{8} \mathrm{H}_{15}{ }^{+}$ & fragment Octanal \\
$\mathbf{1 2 9 . 1 2 7}$ & $\mathrm{C}_{8} \mathrm{H}_{17} \mathrm{O}^{+}$ & Octanal \\
& & \\
& &
\end{tabular}




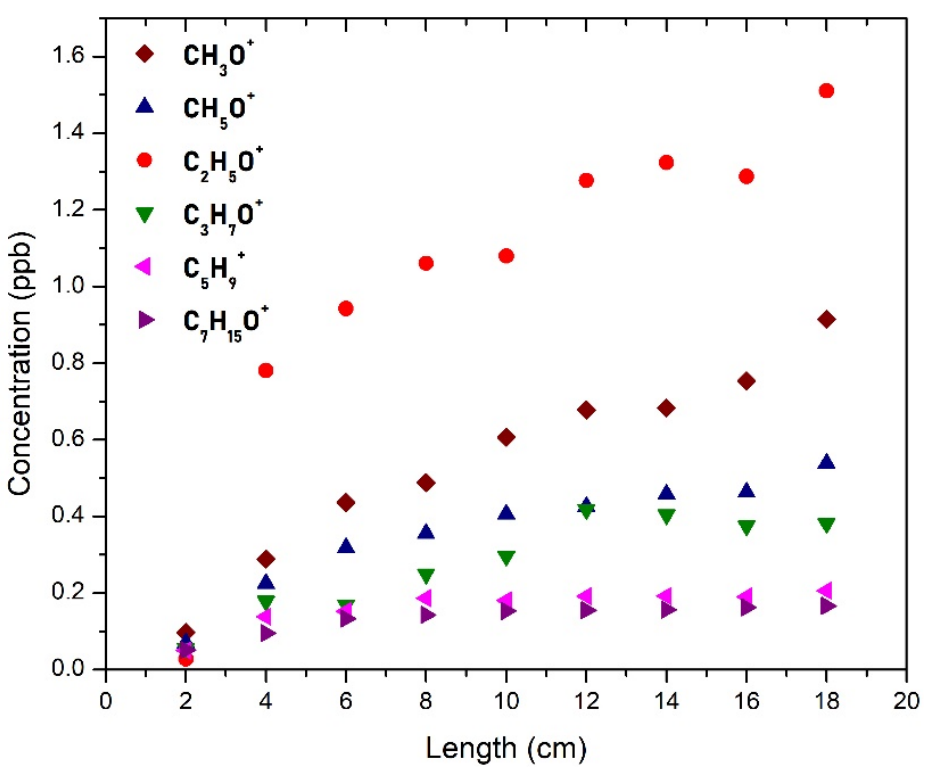

Figure 2: Product concentration profile for each position/residence time along the reactor. For initial butanol concentration of $20 \mathrm{ppb}$, dry conditions, $\mathrm{T}=20^{\circ} \mathrm{C}, 7$ lamps, mass of ATD $=110 \mathrm{mg}$.

To explore whether these products are arising from "freshly" up taken butanol or from adsorbed molecules, a film was exposed to gas phase butanol in the dark until surface saturation (i.e., constant butanol signal). Maintaining the butanol flow throughout the reactor, the lights were then switched on and off in the following sequence: 1) 30 minutes two lamps on; 2) 30 minutes four lamps on; 3) 1 hour all lamps off; 4) 30 minutes 6 lamps on. We observed (see Figure 3) production of different compounds $\left(\mathrm{CH}_{3} \mathrm{O}+, \mathrm{C}_{2} \mathrm{H}_{5} \mathrm{O}+, \mathrm{C}_{3} \mathrm{H}_{7} \mathrm{O}+, \mathrm{C}_{5} \mathrm{H}_{9}+\right.$, and $\left.\mathrm{C}_{7} \mathrm{H}_{15} \mathrm{O}+\right)$ immediately after the lights were turned on, with increasing intensity at higher light fluxes. Nevertheless, there was no drop in the gas phase butanol concentration, suggesting that products were formed from butanol already adsorbed on the surface. Product formation was quantified (subtracting the background value from the concentration during irradiation) for each round of illumination (number of lamps switched on; Figure 4). Although only major products are shown in Figure 3 and Figure 4, the same minor products listed in Table S3 were also present. Figure 4 clearly demonstrates that irradiation enhanced product formation. It is known that photocatalytic reaction rates are proportional to the radiant flux for low/moderate illumination intensities. ${ }^{44}$ Chapuis et al. ${ }^{45}$ also observed lower product concentrations 268 at lower light intensities, other factors being equal, for the photocatalytic oxidation (PCO) of n- 


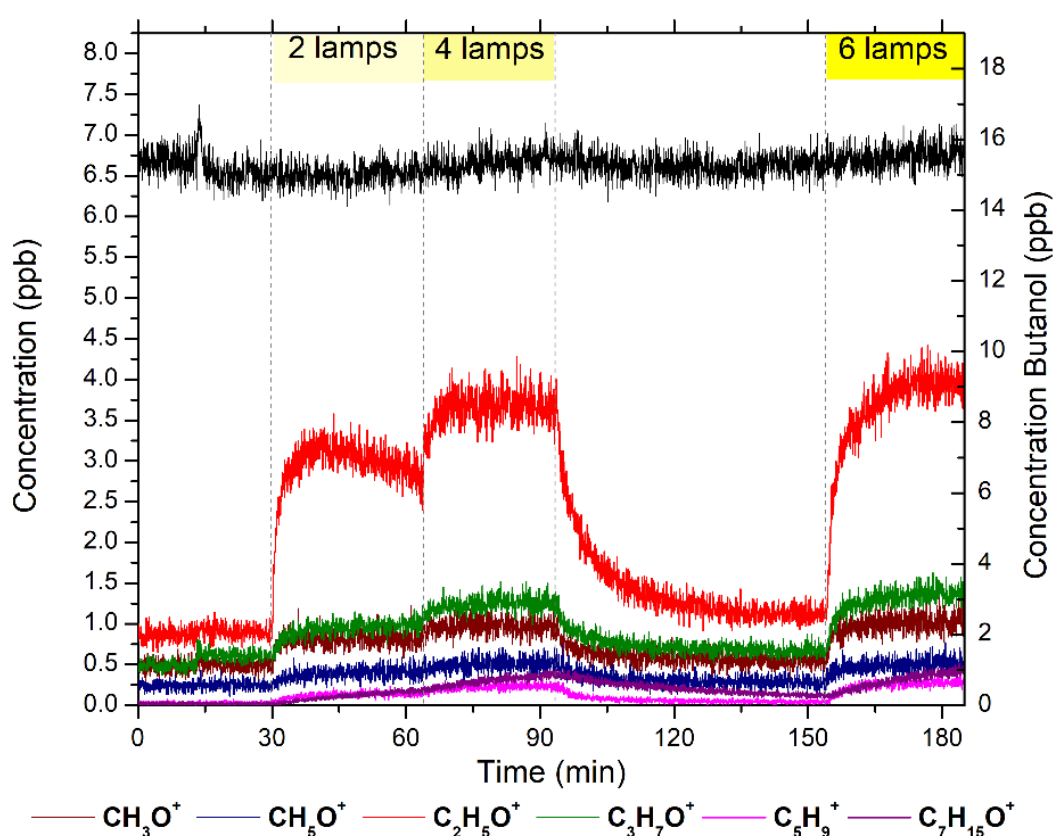

Figure 3: Saturation experiment: Concentration profiles for butanol (right scale) and main products over butanol-saturated ATD surface for different irradiation intensities (2, 4, and 6 lamps, indicated by bars above the graph). Experimental conditions were: Air flow rate $200 \mathrm{ml} / \mathrm{min}$, dry conditions, $\mathrm{T}=20^{\circ} \mathrm{C}$, mass of ATD $=35 \mathrm{mg}$.

Concerning the study of alcohols under atmospheric simulated conditions onto different mineral proxies, mainly small aldehydes, ketones, and carboxylic acids were reported as products. Styler and Donaldson ${ }^{21}$ studied the photooxidation of isopropanol and n-propanol over $\mathrm{TiO}_{2}$ films in a Knudsen cell, operated at much lower pressure than in the current investigation, and identified acetone and propionaldehyde, respectively, as main products. The same authors, Styler, Myers, and Donaldson, ${ }^{46}$ studied the photooxidation of fluorotelomer alcohols onto Mauritanian sand and volcanic ashes and found aldehydic products in the gas phase and perfluorinated carboxylic acids as sorbed products. Recently, Romanias and coworkers ${ }^{32}$ also studied the photochemistry of isopropanol on Gobi natural dust under pure air, reporting the formation of acetone, formaldehyde, acetic acid, and acetaldehyde as products when the dust was illuminated. 


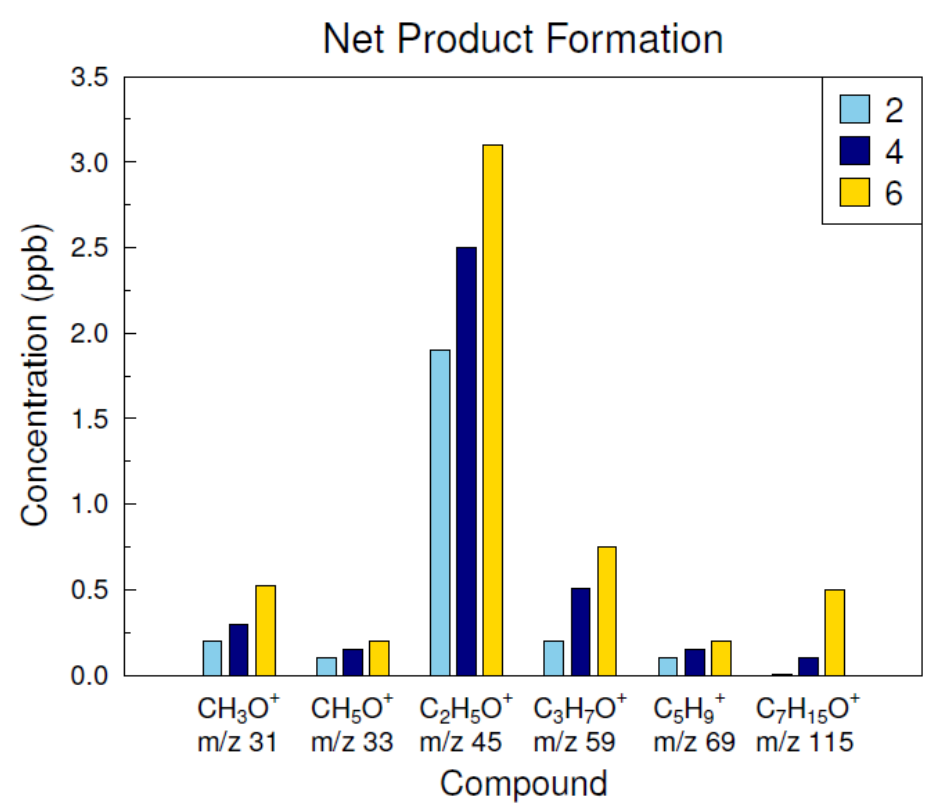

Figure 4: Net product formation of major products for different light intensities during the saturation experiment (Figure 3). The number of lamps is represented by bar color as indicated in the legend.

Most of the available literature for alcohols, and specifically butanol, investigates photocatalytic oxidation (PCO) on $\mathrm{TiO}_{2}$, with the goal of optimizing conditions to mineralize the organic compound. Yao and Feilberg ${ }^{47}$ quantified product formation for the photocatalytic degradation of $52 \mathrm{ppb}$ of n-butanol through $\mathrm{TiO}_{2}$-coated ceramic filters, reporting acetaldehyde, butyraldehyde, propionaldehyde/acetone, ethanol, formic acid, acetic acid, and formaldehyde as potential byproducts. They pointed out, however, that the observed products accounted for only a fraction of the reactant consumption, suggesting that butanol could be directly degraded producing $\mathrm{CO}_{2}$ and water.

In our case, the total yield (sum of the yield of all detected products) is around $30-40 \%$, implying that either all of the adsorbed butanol is not converted into products, or some butanol is converted into non-volatile products that accumulate on the surface or yet is mineralized to $\mathrm{CO}_{2}$ and water. Butanal can be expected to be one of the first intermediates from the butanol oxidation, it is 
therefore interesting to note that we did not detect it. It was however detected in studies investigating the oxidation on pure $\mathrm{TiO}_{2}$ at much higher concentrations than ours. ${ }^{47-51}$ In addition to butanal, propionaldehyde, acetaldehyde, 1-propanol, and ethanol were also found by those authors. It is worthwhile to note that all of these studies investigated oxidation on pure $\mathrm{TiO}_{2}$ at much higher concentrations than used in this study. Nevertheless, this study generally agrees with previous reports that, mineral dust (ATD containing 2.0 - 5.0 wt $\% \mathrm{Fe}_{2} \mathrm{O}_{3}$ and 0.5 - 1 wt\% $\mathrm{TiO}_{2}$ ) can promote photooxidation of an organic compound on its surface similar to pure semiconductors such as $\mathrm{TiO}_{2}$.

Gas phase products give some insight into the butanol degradation mechanism under our experimental conditions. We propose that during photooxidation adsorbed butanol is first directly oxidized to an aldehyde by photo-generated holes or $\mathrm{OH}$ radicals from residual water on the surface.

$$
\mathrm{TiO}_{2}+h v \leftrightarrows h_{v b}^{+}+e_{c b}^{-}
$$

$$
\mathrm{H}_{2} \mathrm{O}_{(a d s)}+h_{v b}^{+} \rightarrow{ }^{\bullet} \mathrm{OH}+\mathrm{H}^{+}
$$

$$
\mathrm{R}-\mathrm{CH}_{2}-\mathrm{OH}_{(\mathrm{ads})}+\mathrm{h}^{+}(\mathrm{or} \bullet \mathrm{OH}) \rightarrow \mathrm{R}-\mathrm{CHO}+\mathrm{H}^{+}
$$

to those proposed by other authors, ${ }^{48,52,53}$ with aldehydes being converted to shorter chain aldehydes and/or alcohols.

As presented by Ye et al., ${ }^{53}$ aldehydes are oxidized via two pathways, either through the C(n) acid, or by direct conversion to the $\mathrm{C}(\mathrm{n}-1)$ aldehyde. No acids were detected here, which may be due to their lower volatility or their high affinity for the dust surface (and tubing). Alcohols such as propanol and ethanol can also remain adsorbed on dust surface. ${ }^{45}$ A global mechanism is suggested in Figure 5. In general, we can say:

$$
R-\mathrm{OH}+h^{+}(\mathrm{or} \cdot \mathrm{OH}) \rightarrow \mathrm{R}-\mathrm{CHO} \stackrel{\mathrm{O}_{2}}{\longrightarrow} \mathrm{R}-\mathrm{COOH}+h^{+} \rightarrow \begin{aligned}
& R_{(n-1)} \mathrm{CHO} \\
& R_{(n-1)}-\mathrm{OH}
\end{aligned}
$$


325 Some studies highlight the contribution of superoxide radical and other radical species derived from 326 oxygen. ${ }^{52,54}$ The superoxide radical may contribute, for instance, to charge separation (between $e_{c b}^{-}$ 327 and $h_{v b}^{+}$). Molecular $\mathrm{O}_{2}$ is also very important, as it can directly oxidize the aldehyde to an acid ${ }^{48}$ or 328 react with alkyl radicals, ${ }^{52}$ forming a hydroxylated peroxyl radical and $\mathrm{HOO}^{\bullet}$ radicals. In anhydrous 329 systems, $\mathrm{O}_{2}$ is the active oxidizing species, and its ionosorbates are the only negatively charged 330 species able to react with holes. ${ }^{33}$

$$
\begin{gathered}
O_{2(g)} \rightarrow 2 O_{a d s} \\
O_{a d s}+e^{-} \rightarrow O_{a d s}^{-} \\
O_{a d s}^{-}+h^{+} \rightarrow O_{a d s}^{*}
\end{gathered}
$$

Additionally, intermediary reactions in the oxidation mechanism may lead to the formation of radicals, resulting in the propagation of chain reactions ${ }^{52}$ involving $\mathrm{O}_{2} \cdot{ }^{54}$ Recombination of radicals is then likely to occur, resulting in products of higher molar mass than the initial compound.

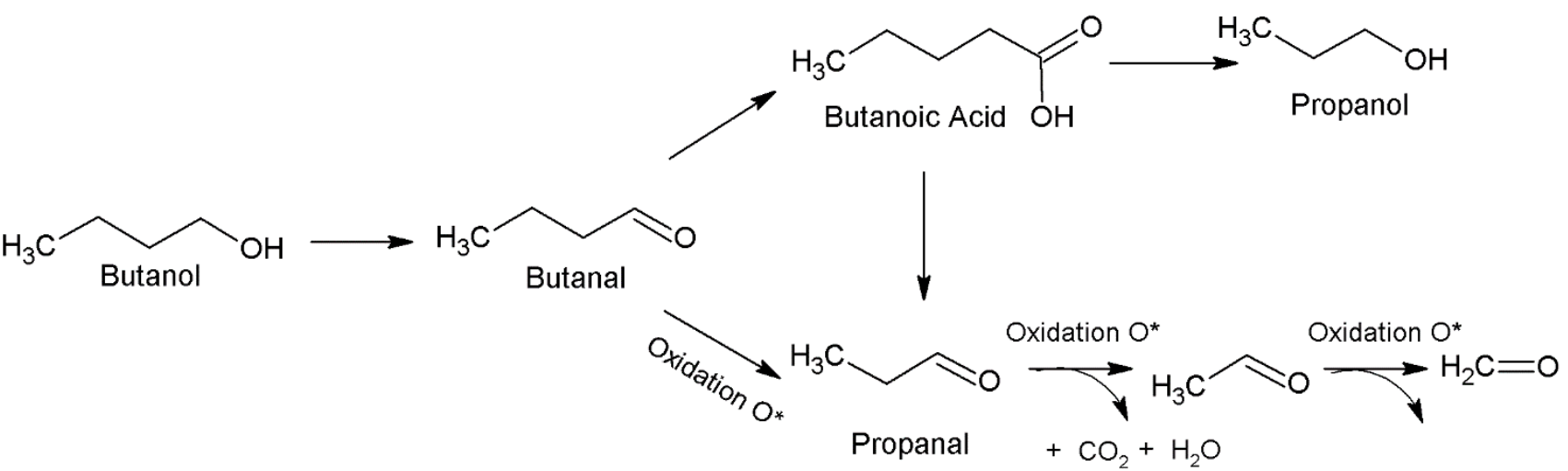

Figure 5: Suggested mechanism for butanol photooxidation on ATD’s surface.

341 Carbonyl compounds were the predominant products observed in the gas phase. Aldehydes and 342 ketones absorb at UV-Vis wavelengths (>290 nm), acting as radical precursors for further 343 photochemical reactions. On the other hand, alcohols, including butanol, do not absorb light at these 
wavelengths and therefore generally have longer lifetimes in the troposphere. ${ }^{55}$ We emphasize that mineral dust plays an important role not only acting as a scavenger for alcohol molecules, but also in converting them into more reactive species.

\section{Atmospheric Implications}

We presented the effect of ambient conditions such as temperature, relative humidity, and light intensity on an oxygenated organic compound uptake on realistic mineral dust particles. Uptake was maximized at low temperature and low humidity.

We estimated the lifetime of butanol due to its heterogeneous photooxidation on mineral dust surfaces. The calculation used the first order rate constant under atmospheric conditions i.e., with the uptake coefficient measured at $20 \mathrm{ppbv}$ of butanol, for dry conditions, at $20^{\circ} \mathrm{C}$ under a real UV-A (315-400 nm) irradiance, determined using the Quick TUV model, for latitude of $40^{\circ}$ North at noon during equinox day, or solar zenith angle of $40^{\circ}$. For very high dust loadings (surface area density of $0.052 \mathrm{~m}^{2} \mathrm{~m}^{3}$ ), the butanol lifetime was found to be 1.48 days whereas for regular clean days (surface area density of $1 \times 10^{-4} \mathrm{~m}^{2} \mathrm{~m}^{-3}$ ) it was 770 days. By comparison, the butanol lifetime due to $\mathrm{OH}$ radical reaction is estimated as 1.4 days. ${ }^{55}$ As a consequence, this butanol removal pathway can only be effective in a dust plume.

More importantly, the photochemistry described here occurs on illuminated mineral dust, with adsorbed organic compounds typically being oxidized to shorter and more volatile products. Butanol, for instance, will produce aldehydes such as formaldehyde, acetaldehyde, and propionaldehyde which are potential sources of atmospheric radicals. More complex products (e.g., dimers of reaction intermediates) were also formed in small amounts. In other words, mineral dust can be regarded as a reservoir for such compounds, transporting pollution for source regions to remote places and may transport, where tens of pptv of aldehydes may be a significant contribution to their actual concentrations. Overall, mineral dust is not inert and opens new photochemical pathways that so far 
370 have not been considered in current atmospheric models.

373 Acknowledgements

374 The authors gratefully acknowledge the Brazilian National Council for Scientific and Technological 375 Development-CNPq, Brazil for the financial support (PhD fellowship of M. P.)

\section{Supporting Information}

378 Lamp calibrations (total irradiance for different configuration of lamps) are presented in Figures S1 379 and Table S1. A schematic overview of the experimental setup is given in Figure S2. Dependence of 380 geometric uptake coefficient on butanol and the BET uptake coefficients are shown in Figure S3a and 381 S3b, respectively. BET uptake coefficients as a function of butanol concentration, reactor temperature, 382 relative humidity, and number of lamps are shown in Figure S4, S5, and S6, S8. Butanol loss upon 383 exposing an ATD film to different relative humidity levels under dark conditions is presented in 384 Figure S7. Details about product identification and PTR-MS standards are also given in the SI in 385 Figure S9 and Tables S2 and S3. 


\section{References}

389 (1) Kaufman, Y. J. Dust Transport and Deposition Observed from the Terra-Moderate 390

(2) Sa’id, R. S. Dust Aerosols And Climate: A Brief Review. Adv. Sci. Technol. 2012, 6 (2), $115-122$.

(4) Underwood, G. M.; Li, P.; Usher, C. R.; Grassian, V. H. Determining Accurate Kinetic

Resolution Imaging Spectroradiometer (MODIS) Spacecraft over the Atlantic Ocean. $J$. Geophys. Res. 2005, 110 (D10), D10S12.

(3) Usher, C. R.; Michel, A. E.; Grassian, V. H. Reactions on Mineral Dust. Chem. Rev. 2003, 103 (12), 4883-4939.

Parameters of Potentially Important Heterogeneous Atmospheric Reactions on Solid Particle Surfaces with a Knudsen Cell Reactor. J. Phys. Chem. A 2000, 104 (4), 819-829.

(5) Seisel, S.; Borensen, C.; Vogt, R.; Zellner, R. Kinetics and Mechanism of the Uptake of N2O5 on Mineral Dust at 298 K. Atmos. Chem. Phys. 2005, 5 (12), 3423-3432.

(6) Hanisch, F.; Crowley, J. N. Ozone Decomposition on Saharan Dust: An Experimental Investigation. Atmos. Chem. Phys. 2003, 3 (1), 119-130.

(7) Adams, J. W.; Rodriguez, D.; Cox, R. A. The Uptake of $\mathrm{SO}_{2}$ on Saharan Dust: A Flow Tube Study. Atmos. Chem. Phys. 2005, 5 (10), 2679-2689.

(8) Carlos-Cuellar, S.; Li, P.; Christensen, A. P.; Krueger, B. J.; Burrichter, C.; Grassian, V. H. Heterogeneous Uptake Kinetics of Volatile Organic Compounds on Oxide Surfaces Using a Knudsen Cell Reactor: Adsorption of Acetic Acid, Formaldehyde, and Methanol on $\alpha$-Fe $2 \mathrm{O}$ 3 , $\alpha$-Al 2 O 3 , and SiO 2. J. Phys. Chem. A 2003, 107 (21), 4250-4261.

(9) Li, P.; Perreau, K. A.; Covington, E.; Song, C. H.; Carmichael, G. R.; Grassian, V. H. Heterogeneous Reactions of Volatile Organic Compounds on Oxide Particles of the Most Abundant Crustal Elements: Surface Reactions of Acetaldehyde, Acetone, and 
Propionaldehyde on $\mathrm{SiO} 2$, $\mathrm{Al} 2 \mathrm{O} 3$, Fe $2 \mathrm{O} 3$, TiO 2 , and CaO. J. Geophys. Res. Atmos. 2001, 106 (D6), 5517-5529.

(10) Herrmann, J.-M. Heterogeneous Photocatalysis: Fundamentals and Applications to the Removal of Various Types of Aqueous Pollutants. Catal. Today 1999, 53 (1), 115-129.

(11) Alberici, R. M.; Jardim, W. F. Photocatalytic Destruction of VOCs in the Gas-Phase Using Titanium Dioxide. Appl. Catal. B Environ. 1997, 14 (1-2), 55-68.

(12) Litter, M. Heterogeneous Photocatalysis Transition Metal Ions in Photocatalytic Systems. Appl. Catal. B Environ. 1999, 23 (2-3), 89-114.

(13) Wang, N.; Zheng, T.; Zhang, G.; Wang, P. A Review on Fenton-like Processes for Organic Wastewater Treatment. J. Environ. Chem. Eng. 2016, 4 (1), 762-787.

(14) Chen, H.; Nanayakkara, C. E.; Grassian, V. H. Titanium Dioxide Photocatalysis in Atmospheric Chemistry. Chem. Rev. 2012, 112 (11), 5919-5948.

(15) George, C.; Ammann, M.; D’Anna, B.; Donaldson, D. J.; Nizkorodov, S. a. Heterogeneous Photochemistry in the Atmosphere. Chem. Rev. 2015, 115 (10), 4218-4258.

(16) Nicolas, M.; Ndour, M.; Ka, O.; D’Anna, B.; George, C. Photochemistry of Atmospheric Dust: Ozone Decomposition on Illuminated Titanium Dioxide. Environ. Sci. Technol. 2009, 43 (19), 7437-7442.

(17) Ndour, M.; D’Anna, B.; George, C.; Ka, O.; Balkanski, Y.; Kleffmann, J.; Stemmler, K.; Ammann, M. Photoenhanced Uptake of NO 2 on Mineral Dust: Laboratory Experiments and Model Simulations. Geophys. Res. Lett. 2008, 35 (5), L05812.

(18) Dupart, Y.; King, S. M.; Nekat, B.; Nowak, A.; Wiedensohler, A.; Herrmann, H.; David, G.; Thomas, B.; Miffre, A.; Rairoux, P.; et al. Mineral Dust Photochemistry Induces Nucleation Events in the Presence of SO2. Proc. Natl. Acad. Sci. U. S. A. 2012, 109 (51), 20842-20847.

(19) Huang, L.; Zhao, Y.; Li, H.; Chen, Z. Kinetics of Heterogeneous Reaction of Sulfur Dioxide 
on Authentic Mineral Dust: Effects of Relative Humidity and Hydrogen Peroxide. Environ. Sci. Technol. 2015, 49 (18), 10797-10805.

(20) Zein, A. El; Romanias, M. N.; Bedjanian, Y. Heterogeneous Interaction of H2O2 with Arizona Test Dust. J. Phys. Chem. A 2014, 118 (2), 441-448.

(21) Styler, S. a; Donaldson, D. J. Photooxidation of Atmospheric Alcohols on Laboratory Proxies for Mineral Dust. Environ. Sci. Technol. 2011, 45 (23), 10004-10012.

(23) Ndour, M.; Conchon, P.; D’Anna, B.; Ka, O.; George, C. Photochemistry of Mineral Dust Surface as a Potential Atmospheric Renoxification Process. Geophys. Res. Lett. 2009, 36 (5), L05816.

(24) Dupart, Y.; Fine, L.; D’Anna, B.; George, C. Heterogeneous Uptake of NO2 on Arizona Test Dust under UV-A Irradiation: An Aerosol Flow Tube Study. Aeolian Res. 2014, 15 (2), 4551.

(25) Spanel, P.; Smith, D. SIFT Studies of the Reactions of H3O+, NO+ and O2+ with a Series of Alcohols. Int. J. Mass Spectrom. Ion Process. 1997, 167-168 (2), 375-388.

(26) Španěl, P.; Ji, Y.; Smith, D. SIFT Studies of the Reactions of H3O+, NO+ and O2+ with a Series of Aldehydes and Ketones. Int. J. Mass Spectrom. Ion Process. 1997, 165-166, 25-37.

(27) Španěl, P.; Smith, D. SIFT Studies of the Reactions of H3O+, NO+ and O2+ with Several Ethers. Int. J. Mass Spectrom. Ion Process. 1998, 172 (3), 239-247.

(28) Smith, D.; Chippendale, T. W. E.; Španěl, P. Reactions of the Selected Ion Flow Tube Mass Spectrometry Reagent Ions $\mathrm{H3O}+$ and NO+ with a Series of Volatile Aldehydes of Biogenic Significance. Rapid Commun. Mass Spectrom. 2014, 28 (17), 1917-1928.

(29) de Gouw, J.; Warneke, C. Measurements of Volatile Organic Compounds in the Earth’s 
Atmosphere Using Proton-Transfer-Reaction Mass Spectrometry. Mass Spectrom. Rev. 2007, 26 (2), 223-257.

462

(30) Murphy, D. M.; Fahey, D. W. Mathematical Treatment of the Wall Loss of a Trace Species in Denuder and Catalytic Converter Tubes. Anal. Chem. 1987, 59 (23), 2753-2759.

(31) Li, G.; Su, H.; Li, X.; Kuhn, U.; Meusel, H.; Hoffmann, T.; Ammann, M.; Pöschl, U.; Shao, M.; Cheng, Y. Uptake of Gaseous Formaldehyde by Soil Surfaces: A Combination of Adsorption/desorption Equilibrium and Chemical Reactions. Atmos. Chem. Phys. 2016, 16 (15), 10299-10311.

(32) Romanias, M. N.; Zeineddine, M. N.; Gaudion, V.; Lun, X.; Thevenet, F.; Riffault, V. Heterogeneous Interaction of Isopropanol with Natural Gobi Dust. Environ. Sci. Technol. 2016, 50 (21), 11714-11722.

(33) Herrmann, J.-M. Active Agents in Heterogeneous Photocatalysis: Atomic Oxygen Species vs. OH.cntdot. Radicals: Related Quantum Yields. Helv. Chim. Acta 2001, 84 (9), 27312750.

(34) Liu, Q.; Wang, Y.; Wu, L.; Jing, B.; Tong, S.; Wang, W.; Ge, M. Temperature Dependence of the Heterogeneous Uptake of Acrylic Acid on Arizona Test Dust. J. Environ. Sci. 2017, 53, 107-112.

(35) Tang, M.; Cziczo, D. J.; Grassian, V. H. Interactions of Water with Mineral Dust Aerosol: Water Adsorption, Hygroscopicity, Cloud Condensation, and Ice Nucleation. Chem. Rev. 2016, 116 (7), 4205-4259.

(36) Sassine, M.; Burel, L.; D’Anna, B.; George, C. Kinetics of the Tropospheric Formaldehyde Loss onto Mineral Dust and Urban Surfaces. Atmos. Environ. 2010, 44 (40), 5468-5475.

(37) El Zein, A.; Romanias, M. N.; Bedjanian, Y. Kinetics and Products of Heterogeneous Reaction of HONO with Fe2O3 and Arizona Test Dust. Environ. Sci. Technol. 2013, 47 (12), 
(38) Bedjanian, Y.; Romanias, M. N.; El Zein, A. Uptake of $\mathrm{HO}_{2}$ Radicals on Arizona Test Dust. Atmos. Chem. Phys. 2013, 13 (13), 6461-6471.

(39) Gustafsson, R. J.; Orlov, A.; Badger, C. L.; Griffiths, P. T.; Cox, R. a.; Lambert, R. M. A Comprehensive Evaluation of Water Uptake on Atmospherically Relevant Mineral Surfaces: DRIFT Spectroscopy, Thermogravimetric Analysis and Aerosol Growth Measurements. Atmos. Chem. Phys. Discuss. 2005, 5 (4), 7191-7210.

(40) Navea, J. G.; Chen, H.; Huang, M.; Carmichel, G. R.; Grassian, V. H. A Comparative Evaluation of Water Uptake on Several Mineral Dust Sources. Environ. Chem. 2010, 7 (2), $162-170$.

(41) Rubasinghege, G.; Grassian, V. H. Role(s) of Adsorbed Water in the Surface Chemistry of Environmental Interfaces. Chem. Commun. (Camb). 2013, 49 (30), 3071-3094.

(42) Schripp, T.; Fauck, C.; Salthammer, T. Interferences in the Determination of Formaldehyde via PTR-MS: What Do We Learn from M/z 31? Int. J. Mass Spectrom. 2010, 289 (2-3), $170-172$.

(43) Inomata, S.; Tanimoto, H.; Kameyama, S.; Tsunogai, U.; Irie, H.; Kanaya, Y.; Wang, Z. Technical Note: Determination of Formaldehyde Mixing Ratios in Air with PTR-MS: Laboratory Experiments and Field Measurements. Atmos. Chem. Phys. 2008, 8 (2), 273-284.

(44) Herrmann, J.-M. Fundamentals and Misconceptions in Photocatalysis. J. Photochem. Photobiol. A Chem. 2010, 216 (2-3), 85-93.

(45) Chapuis, Y.; Klvana, D.; Guy, C.; Kirchnerova, J. Photocatalytic Oxidation of Volatile Organic Compounds Using Fluorescent Visible Light. J. Air Waste Manage. Assoc. 2002, 52 (7), 845-854.

(46) Styler, S. A.; Myers, A. L.; Donaldson, D. J. Heterogeneous Photooxidation of Fluorotelomer 
Alcohols: A New Source of Aerosol-Phase Perfluorinated Carboxylic Acids. Environ. Sci. Technol. 2013, 47 (12), 6358-6367.

(47) Yao, H.; Feilberg, A. Characterisation of Photocatalytic Degradation of Odorous Compounds Associated with Livestock Facilities by Means of PTR-MS. Chem. Eng. J. 2015, 277, 341-

(49) Kirchnerova, J.; Herrera Cohen, M. L.; Guy, C.; Klvana, D. Photocatalytic Oxidation of NButanol under Fluorescent Visible Light Lamp over Commercial TiO2 (Hombicat UV100 and Degussa P25). Appl. Catal. A Gen. 2005, 282 (1-2), 321-332.

(50) Peral, J.; Ollis, D. F. Heterogeneous Photocatalytic Oxidation of Gas-Phase Organics for Air Purification: Acetone, 1-Butanol, Butyraldehyde, Formaldehyde, and M-Xylene Oxidation. J. Catal. 1992, 136 (2), 554-565.

(51) Blake, N. R.; Griffin, G. L. Selectivtty Control during the Photoassisted Oxidatlon of 1Butanol on Titanium Dioxide. J. Phys. Chem. 1988, 92 (13), 5697-5701.

(52) Nimlos, M. R.; Wolfrum, E. J.; Brewer, M. L.; Fennell, J. a; Bintner, G. Gas-Phase Heterogeneous Photocatalytic Oxidation of Ethanol: Pathways and Kinetic Modeling. Environ. Sci. Technol. 1996, 30 (10), 3102-3110.

(53) Ye, X.; Chen, D.; Gossage, J.; Li, K. Photocatalytic Oxidation of Aldehydes: Byproduct Identification and Reaction Pathway. J. Photochem. Photobiol. A Chem. 2006, 183 (1-2), $35-40$.

(54) Hirakawa, T.; Daimon, T.; Kitazawa, M.; Ohguri, N.; Koga, C.; Negishi, N.; Matsuzawa, S.; Nosaka, Y. An Approach to Estimating Photocatalytic Activity of TiO2 Suspension by 

Monitoring Dissolved Oxygen and Superoxide Ion on Decomposing Organic Compounds. J. Photochem. Photobiol. A Chem. 2007, 190 (1), 58-68.

534 (55) Mellouki, A.; Wallington, T. J.; Chen, J. Atmospheric Chemistry of Oxygenated Volatile 535 Organic Compounds: Impacts on Air Quality and Climate. Chem. Rev. 2015, 115 (10), 3984536 4014. 